\title{
Trends in repeated pregnancy among adolescents in the Philippines from 1993 to 2013
}

Joemer C. Maravilla $a^{1,2^{*}}$ D, Kim S. Betts ${ }^{1,2}$ and Rosa Alati ${ }^{1,2,3}$

\begin{abstract}
Objective: The extent of repeated pregnancy (RP) and repeated birth (RB) among adolescents aged 15-19 is still unknown in the Philippines despite the health and socio-economic consequences. This study aims to investigate the RP and RB prevalence trends in the Philippines from 1993 to 2013.

Methods: A total of 7091 women aged 15-24 who experienced at least one pregnancy were captured in the Philippine demographic health surveys from 1993 to 2013. Annual RP and RB prevalence per age group in three and five categories were calculated and stratified by region, type of residence and wealth index. Cochran-Armitage tests and multivariate logistic regression were applied to determine trend estimates.

Results: Compared to women aged 19-21 years and 22-24 years, for which decreasing patterns were found, RP ( Adjusted Odds ratio ( $A O R=0.96 ; 95 \%$ Confidence interval $(C l)=0.82-1.11)$ and $R B(A O R=0.90 ; C l=0.73-1.10)$ trends among 15-18 year olds showed negligible reduction over the 20 years. From a baseline prevalence of 20.39\% in 1993, the prevalence of RP among adolescents had only reduced to $18.06 \%$ by 2013 . Moreover, the prevalence of RB showed a negligible decline from 8.49\% in 1993 to $7.80 \%$ in 2013. Although RP and RB prevalence were generally found more elevated in poorer communities, no differences in trends were noted across wealth quintiles. Conclusion: For two decades, the Philippines has shown a constant and considerably high RP prevalence. Further investigation, not only in the Philippines but also in other developing countries, is necessary to enable development of secondary prevention programs.
\end{abstract}

\section{Plain English summary}

Despite high and stable levels of adolescent fertility in the Philippines, no specific research has been conducted to specifically measure the trend and magnitude of repeated adolescent pregnancy, which is defined as an adolescent who has had at least two pregnancies. Repeated pregnancy, therefore needs to be investigated as it reflects not only the reproductive health of adolescent mothers but also disparities in service delivery of health, education and welfare support to adolescents after their first pregnancy.

We used the Philippine Demographic and Health Surveys to sample 7091 women aged 15-24 who

\footnotetext{
* Correspondence: joemer.maravilla@uqconnect.edu.au

'School of Public Health, The University of Queensland, Herston, QLD,

Australia

${ }^{2}$ Institute for Social Science Research, The University of Queensland,

Indooroopilly, QLD, Australia

Full list of author information is available at the end of the article
}

experienced at least one pregnancy. Annual RP and RB prevalence per age group in three and five categories were calculated and stratified by region, type of residence and wealth quintile. Trends were statistically analysed using Cochran-Armitage tests and multivariate logistic regression.

While a decline was observed in 19-21 and 22-24 year olds, we found a constant prevalence of one in every five in 15-18 years old from 1993 to 2013. This trend was evident across all regions, types of residence and socio-economic status. Our analysis also found that those from the poorest wealth quintile demonstrated a heightened risk of repeated pregnancy compared to other quintiles. The non-decreasing prevalence trend of repeated pregnancy among adolescents indicated the need for secondary prevention programs particularly for the poorest households. Epidemiological investigations are also necessary to explore the causes and impact of 
repeated pregnancy on maternal, child and neonatal health, not only in the Philippines, but also among other low- and middle-income countries.

\section{Introduction}

The adolescent pregnancy epidemic in the Philippines has been acknowledged as one of the worst in the Western Pacific Region [1] with a recent prevalence of $13.6 \%$ among 15-19 year olds. The Philippines is the only country in this region with no significant decline in adolescent fertility in the past decades [2] from 56 per 1000 in 1973 to 57 per 1000 in 2013 [2, 3]. In order to address this entrenched public health issue, preventive policies and programs have been implemented $[4,5]$, and epidemiological studies have been developed to provide evidence of the current sexual health and behaviour of Filipino adolescents [6]. However, these measures have put little emphasis on the more serious problem of repeated adolescent pregnancies.

Repeated adolescent pregnancy, which is defined as a subsequent pregnancy among adolescents aged 1019 years [7] is known to affect around 18\% of adolescent mothers in the USA [7], Europe [8], and Australia [9]. Despite the evident chance of repeated adolescent pregnancy especially within 2 years postpartum [10], current research is unable to clearly establish its magnitude in developing countries such as the Philippines, nor how the trends have changed across time [11-13]. Although a World Health Organization (WHO) multi-country report [14] discussed the relationship between age and parity among Filipino adolescents, this study did not assess the prevalence of multi parity as its primary measure.

As a marker for adolescent reproductive health, repeated pregnancy reflects health disparities particularly among the disadvantaged adolescent population. Repeated pregnancy also indicates poor distribution and unequal access to reproductive health services [15] and inadequate service capacity of individual localities. It relates to low educational attainment, limited employment opportunities and poverty among adolescent mothers $[15,16]$. It has been shown that repeated adolescent pregnancy leads to an increase in national health and welfare expenditure as a consequence of the long-term dependency of adolescents and their families on government assistance $[15,17]$.

An increasing trend of adolescent sexual activity [3] ongoing poor compliance with modern contraceptives $[2,18]$ and inadequate use of family planning services all suggest that repeated adolescent pregnancy is highly prevalent in the Philippines [12]. Analysis of existing nationally representative data can be helpful in evaluating the extent of this public health problem. In this study, we aim to determine the prevalence of repeated pregnancies and births among adolescents and young adults from a series of national surveys conducted between 1993 and 2013. Moreover, we intend to analyze the trend of repeated pregnancies and births by age groupings and potential macro-level confounders across two decades, with resulting trends perhaps reflecting the effectiveness of existing policies and programs in addressing this under-recognized adolescent health problem.

\section{Methods \\ Population and sample}

This study used the Philippine Demographic and Health Survey (DHS) from 1993, 1998, 2003, 2008, and 2013 which are cross-sectional surveys conducted every 5 years. This nationally representative survey involved a multi-stage sampling design up to the household level with enumeration areas distributed by region and type of residence using the most recent national census as its sampling frame. All women in the selected households which includes adolescents aged 15-19 years and young adults aged 20-24 years were interviewed using the Individual Woman's Questionnaire. This survey therefore excludes adolescents aged below 15 years. As shown in Appendix, the majority of the survey sample belonged to these age brackets which we will refer to as adolescents for the succeeding parts of this paper.

\section{Outcome and socio-geographic measures Repeated adolescent pregnancy/birth}

An adolescent aged 15-19 years was considered as having experienced repeated pregnancy (RP) if she had experienced at least two pregnancies, including current pregnancies, which either resulted in a live birth and/or pregnancy loss. A case of repeated birth (RB) was defined as an adolescent with at least two live births. These definitions were adapted from related review papers [8] and the Centers for Disease Control and Prevention [7].

\section{Year}

Survey year was considered as a continuous variable in the analysis to measure the trend because of equal intervals between survey years. Thus, each unit increase in year variable translates to an actual five-year increase.

\section{Age}

Respondents were categorized by age into three and five groups. The three age groups include "15-18" which considers the legal age of consent (18) in the Philippines, "19-21" as the transition period, and " $22-24$ " as young adults [19]. In sensitivity analysis we further subdivided age into five groups (i.e. "15-16", "17-18", "19-20", "21-22", and "22-24") to analyze in detail the trends per age. 


\section{Socio-geographic variables}

Region refers to the three main island groups: Luzon, Visayas, and Mindanao. We disaggregated and compared all estimates by region since each island group has unique geographical and cultural characteristics. Further disaggregation per administrative region was not pursued, as the number of administrative regions had increased during the 1998. Type of residence was either rural or urban area where the respondent resided at the time of the survey. Based on their household's wealth score, adolescents were grouped into the household wealth quintiles "richest", "richer", "middle", "poorer", and "poorest" class.

\section{Analyses}

We calculated the mean, standard deviation and prevalence rate of RP and RB per year per age group. RP prevalence was calculated by dividing the number of adolescents with RP and the number of adolescents who experienced at least one pregnancy (including those currently pregnant) multiplied by 100 . $\mathrm{RB}$ prevalence on the other hand was calculated by dividing the number of adolescents with $\mathrm{RB}$ and the number of adolescents who experienced at least one livebirth multiplied by 100 . Deformalized survey weights were applied while calculating the prevalence.

We used the ptrendi package in Stata13 to perform Cochran-Armitage tests to determine the prevalence trend per age group using the chi-square statistic and meeting the assumptions of an additive model. Cochran-Armitage test is a modified Pearson's chi-square test which assesses the association between binary (i.e. RP and RB) and ordinal (i.e. year and age) categories. Multivariate logistic regression analysis with interaction effects for age (i.e. age groups using both three and five categories) and year was conducted while using repeated pregnancy and birth as binary outcome variables (i.e. yes or no). We measured the trend between two consecutive survey years to identify which periods had significant changes in prevalence. In addition, we analyzed trends using year and socio-geographic (i.e. region, type of residence, and wealth index) interaction per age group. For the purpose of this analysis, we used the three category age group as this was the only categorization which allowed a sufficient number of cases.

\section{Results}

Among women aged 15-24 years with at least one pregnancy $(n=7091)$, a large proportion $(53.3 \%)$ were found among the 22-24 year olds. Despite the small proportion of adolescents captured by the surveys, the proportion of 15-18 year olds reported in the survey has increased over time from $7.64 \%(n=107)$ in 1993 to $15.55 \%(n=213)$ in 2013 (see Table 1).

\section{Trend analysis per age group}

Cochran-Armitage tests showed an overall decrease in the trend of RP (Chi2 $=127.60 ; p<0.001)$ across 20 years among the 15-24 years old from a weighted RP prevalence (WtPrev $\mathrm{RP}_{\mathrm{RP}}$ ) of $58.12 \%$ in 1993 to $40.58 \%$ in 2013. There was also a general RB (Chi2 $=100.90 ; p<0.001)$ reduction from weighted $\mathrm{RB}$ prevalence $\left(\mathrm{WtPrev}_{\mathrm{RB}}\right)$ of $51.25 \%$ to $35.66 \%$. However, within age groupings this decline was not observed among 15-18 years olds. In Fig. 1, we only found a slight decrease in RP prevalence from $20.39 \%$ in 1993 to $18.06 \%$ in 2013 . RB prevalence also presented a minimal change with 0.69 decline among $15-18$ and 0.80 decline among $17-18$ years olds in this 20-year period (see Fig. 2). Further observations among 17-18 years olds showed a similar RP trend from 22.26 to $18.52 \%$.

Similar results were found in the regression analysis. The RP trend among 15-18 year olds remained virtually unchanged across all surveys from 1993 to 2013 [Odds ratio $(\mathrm{OR})=0.93$; 95\% Confidence interval $(\mathrm{CI})=0.81-$ 1.07]. There was a similar pattern of RB trend in this age group ( $\mathrm{OR}=0.87 ; \mathrm{CI}=0.72-1.06)$ following an apparent increase in prevalence from 1993 to 1998 (OR = 3.29; CI $=1.25-8.62)$. On the other hand, the older age groups showed a significant decline both for RP and RB with unadjusted ORs ranging from 0.83 to 0.87 (see Table 2). Analyses using five age categories showed no significant difference in the trends previously described. Trends among 15-16 and 17-18 year old adolescents remained unchanged, whereas a decreasing trend was apparent for those aged 19-20, 21-22 and 23-24.

Adjustments for regions, types of residence and wealth quintile suggested that the trends were not confounded by these factors across all age groups. Interestingly, wealth index was strongly associated with RP and RB as adolescents from the poorest quintile had shown higher odds in reference to richest quintile $\left(\mathrm{OR}_{\mathrm{RP}}=5.41, \mathrm{CI}=\right.$ 4.31-6.78; $\left.\mathrm{OR}_{\mathrm{RB}}=5.36, \mathrm{CI}=4.17-6.89\right)$. Calculation of weighted prevalence confirmed this association with a WtPrev ${ }_{R P}$ of $59.60 \%$ and WtPrev $\mathrm{RB}_{\mathrm{RB}}$ of $52.50 \%$.

Change of prevalence between two consecutive survey years was also analyzed using the three age categories. We found that there was a decrease in RP prevalence among 15-18 from 1998 to 2003 (OR $=0.52$; $\mathrm{CI}=0.28$ $0.99)$, and among 22-24 from 1993 to $1998(\mathrm{OR}=0.77$; $\mathrm{CI}=0.61-0.97)$ and 2003-2008 (OR $=0.71 ; \mathrm{CI}=0.58-$ 0.88). A drop in RB prevalence was also found among $15-18$ from 1998 to $2003(\mathrm{OR}=0.32$; $\mathrm{OR}=0.13-0.81)$; and among 22-24 from 1993 to $1998(\mathrm{OR}=0.74 ; \mathrm{CI}=$ $0.58-0.93)$.

\section{Trend per socio-geographic variable per age group}

The constant RP trend among 15-18 and the decreasing $\mathrm{RP}$ trend among 22-24 were found in all regions, types 
Table 1 Characteristics of the respondents

\begin{tabular}{|c|c|c|c|c|c|c|c|c|c|c|c|}
\hline \multirow[t]{2}{*}{ Characteristics } & \multicolumn{2}{|l|}{1993} & \multicolumn{2}{|l|}{1998} & \multicolumn{2}{|l|}{2003} & \multicolumn{2}{|l|}{2008} & \multicolumn{2}{|l|}{2013} & \multirow[t]{2}{*}{ TOTAL } \\
\hline & $n$ & $\%$ & $n$ & $\%$ & $n$ & $\%$ & $n$ & $\%$ & $n$ & $\%$ & \\
\hline \multicolumn{12}{|l|}{ Age (in 3 groups) } \\
\hline $15-18$ & 107 & 7.64 & 124 & 9.74 & 128 & 9.54 & 165 & 11.97 & 213 & 12.55 & 737 \\
\hline $19-21$ & 460 & 32.86 & 449 & 35.27 & 429 & 31.97 & 479 & 34.74 & 580 & 34.18 & 2397 \\
\hline $22-24$ & 833 & 59.50 & 700 & 54.99 & 785 & 58.49 & 735 & 53.30 & 904 & 53.27 & 3957 \\
\hline \multicolumn{12}{|l|}{ Age (in 5 groups) } \\
\hline $15-16$ & 14 & 1.00 & 19 & 1.49 & 21 & 1.56 & 33 & 2.39 & 45 & 2.65 & 132 \\
\hline $17-18$ & 93 & 6.64 & 105 & 8.25 & 107 & 7.97 & 132 & 9.57 & 168 & 9.90 & 605 \\
\hline $19-20$ & 268 & 19.14 & 268 & 21.05 & 269 & 20.04 & 300 & 21.75 & 352 & 20.74 & 1457 \\
\hline $21-22$ & 429 & 30.64 & 387 & 30.40 & 385 & 28.69 & 402 & 29.15 & 502 & 29.58 & 2105 \\
\hline $23-24$ & 596 & 42.57 & 494 & 38.81 & 560 & 41.73 & 512 & 37.13 & 630 & 37.12 & 2792 \\
\hline \multicolumn{12}{|l|}{ Region } \\
\hline Luzon & 685 & 48.93 & 523 & 41.08 & 728 & 54.25 & 699 & 50.69 & 870 & 51.27 & 3505 \\
\hline Visayas & 275 & 19.64 & 244 & 19.17 & 187 & 13.93 & 229 & 16.61 & 232 & 13.67 & 1167 \\
\hline Mindanao & 440 & 31.43 & 506 & 39.75 & 427 & 31.82 & 451 & 32.70 & 595 & 35.06 & 2419 \\
\hline \multicolumn{12}{|l|}{ Type of residence } \\
\hline Urban & 604 & 43.14 & 481 & 37.78 & 672 & 50.07 & 554 & 40.00 & 761 & 44.84 & 3072 \\
\hline Rural & 796 & 56.86 & 792 & 62.22 & 670 & 49.93 & 825 & 59.83 & 936 & 55.16 & 4019 \\
\hline \multicolumn{12}{|l|}{ Wealth quintile } \\
\hline Poorest & 420 & 30.00 & 425 & 33.39 & 372 & 27.72 & 377 & 27.00 & 416 & 24.51 & 2010 \\
\hline Poorer & 342 & 24.43 & 355 & 27.89 & 325 & 24.22 & 344 & 25.00 & 414 & 24.40 & 1780 \\
\hline Middle & 292 & 20.86 & 210 & 16.50 & 272 & 20.27 & 256 & 18.56 & 389 & 22.92 & 1419 \\
\hline Richer & 214 & 15.00 & 173 & 14.00 & 203 & 15.00 & 233 & 17.00 & 305 & 17.97 & 1128 \\
\hline Richest & 132 & 9.43 & 110 & 8.64 & 170 & 12.67 & 169 & 12.26 & 173 & 10.19 & 754 \\
\hline With at least 1 birth $^{a}$ & 1260 & 90.00 & 1124 & 88.30 & 1181 & 88.00 & 1163 & 84.34 & 1471 & 86.68 & 6199 \\
\hline With repeated pregnancy & 825 & 58.93 & 680 & 53.42 & 662 & 49.33 & 571 & 41.41 & 704 & 41.48 & 3442 \\
\hline With repeated birth ${ }^{\mathbf{b}}$ & 660 & 25.04 & 532 & 20.18 & 495 & 18.78 & 420 & 15.93 & 529 & 20.07 & 2636 \\
\hline TOTAL $^{+}$ & 1400 & 100 & 1273 & 100 & 1342 & 100 & 1379 & 100 & 1697 & 100 & 7091 \\
\hline
\end{tabular}

Abbreviations: $n$-Number of respondents

${ }^{a}$ Birth pertains to livebirth; ${ }^{b}$ Adolescents with at least 1 pregnancy

Data captured in bold are highly significant

of residence and wealth quintiles (see Table 3). On the other hand, the decline of RP decline among 19-21 was only consistent across regions and types of residence. Only the poorer households showed a 20-year reduction when compared to the other four quintiles.

A similar pattern was observed for RB trend among those aged between 15 and 18 and 22-24. Unlike RP, the trend for RB among 19-21 year olds was inconsistent across the three socio-geographic variables. The decreasing trend was only found in Visayas and Mindanao region, rural communities, and poor wealth quintiles (see Fig. 3).

In each age group, we also conducted adjusted Wald tests to measure the difference of trend estimates between the categories of each socio-geographic variable. No differences were observed for 15-18. For 19-21, differences were only found between the RP trend estimates of poorest and poorer quintiles, and between the RB trend estimates rural and urban communities. For 22-24, differences between the trend estimates of poorest and richest, and between poorer and richest were found both for RP and RB.

\section{Discussions}

Despite the declining trends of RP and RB in older age groups, the prevalence among adolescents younger than 18 years showed no decrease across 20 years of data, remaining stable across all regions, types of residence, and wealth quintiles. The prevalence was high with approximately one in every five adolescents aged 15-18 years with a history of pregnancy experiencing RP while one in every ten of those who had a livebirth experienced $R B$. 


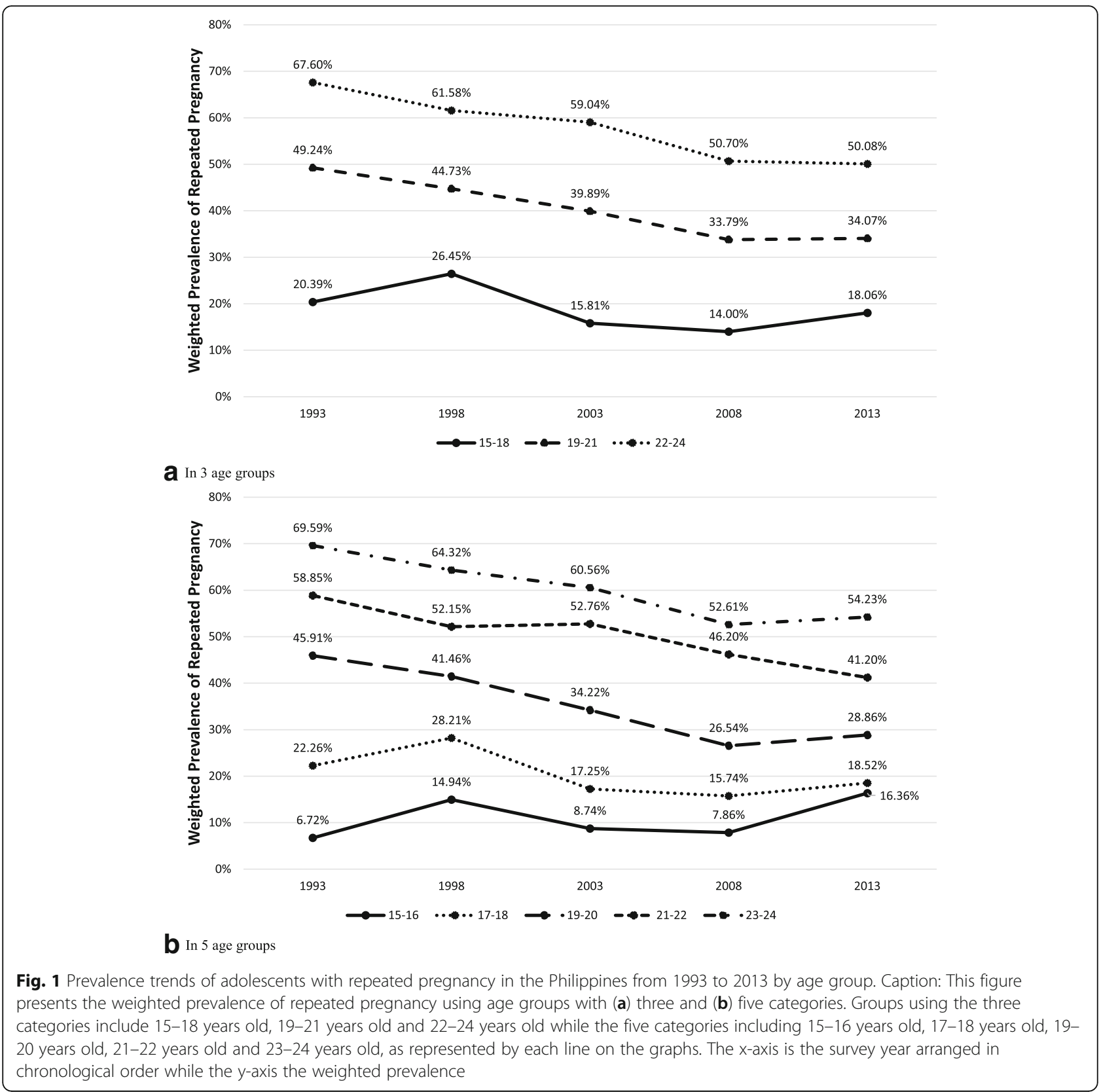

While the decreasing RP and RB trend among young adults can likely be attributed to their improved contraceptive use [20] and awareness of and participation in family planning (FP) strategies [3, 21]. The unchanged trend among adolescents may result from the unique socio-cultural characteristics and FP policies in the Philippines, wherein adolescents are prevented from accessing FP services, even after their first pregnancy. One of the possible explanations for this finding is that the strong influence of the Catholic church at the local level may have affected the health seeking behavior and the implementation of reproductive health programs among adolescents [22, 23].
Unclear and restricted health and health-related policies for adolescent mothers may also play a role. The initial adolescent health policy in the Philippines [24], which aimed to reduce unwanted pregnancies and provide adolescent-friendly health services, did not include strategies for dealing with the prevention of secondary pregnancies $[25,26]$. This may have led to adolescents being discouraged to access essential health information and use birth control methods [23, 27].

Despite emphasizing the importance of health promotion and behavioral change, a recently introduced national law (Responsible Parenthood and Reproductive Health Act of 2012 or RH Law) and framework [4], did 

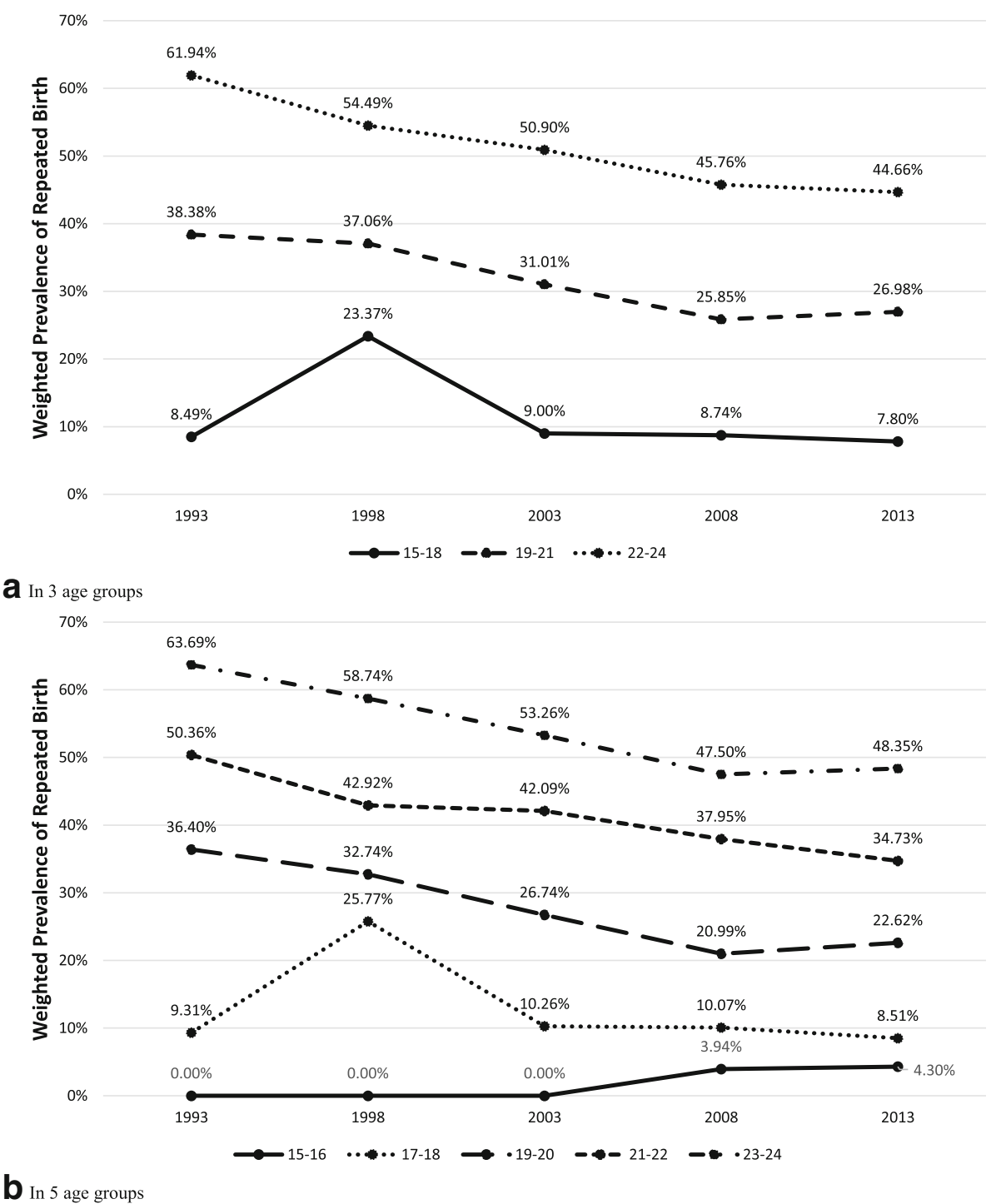

Fig. 2 Prevalence trends of adolescents with repeated birth in the Philippines from 1993 to 2013 by age group. Caption: This figure presents the weighted prevalence of repeated birth using age groups with (a) three and (b) five categories. Groups using the three categories include 1518 years old, 19-21 years old and 22-24 years old while the five categories including 15-16 years old, 17-18 years old, 19-20 years old, 2122 years old and 23-24 years old, as represented by each line on the graphs. The $\mathrm{x}$-axis is the survey year arranged in chronological order while the $y$-axis the weighted prevalence

not embrace specific programmatic actions to address RP. The RH Law still prevents minors (i.e. below 18 years old) from accessing modern methods of contraception without parental consent and does not exempt adolescent mothers and adolescents who experienced miscarriage [28]. This policy restriction has already been found as a deterrent for adolescents to access contraceptives and counselling services in a review of evidence from 16 developing countries [29]. This study suggests that despite the availability of contraception, most of these developing countries retain barriers and restrictions towards the use of birth control methods, particularly among unmarried adolescents. In the context of this social and political environment, the $R P / R B$ trends showed in this paper can be expected to continue for several years to come not only in the Philippines but also in other developing countries.

The role and reach of secondary prevention programs must be clarified due to the limited access to appropriate postnatal services (e.g. contraception, counselling, and educational support) for adolescent mothers. Health workers may also need to be trained to address the unique psychosocial characteristics and support the challenging developmental transition of very young mothers by enhancing adolescents' readiness and decision-making abilities to delay another pregnancy 
Table 2 Trend analysis of repeated pregnancy and birth adolescents from 1993 to 2013 per age group

\begin{tabular}{|c|c|c|c|c|c|c|}
\hline \multirow{2}{*}{$\begin{array}{l}\text { Year x Age } \\
\text { Contrasts }\end{array}$} & \multicolumn{3}{|c|}{ Unadjusted Model } & \multicolumn{3}{|c|}{ Adjusted Model $^{\mathrm{b}}$} \\
\hline & OR & $\mathrm{Cl}$ & $p$-value & $\mathrm{AOR}$ & $\mathrm{Cl}$ & $p$-value \\
\hline \multicolumn{7}{|c|}{ Repeated pregnancy } \\
\hline \multicolumn{7}{|c|}{ Age (in 3 groups) } \\
\hline $15-18$ & 0.93 & $0.81-1.07$ & 0.330 & 0.96 & $0.82-1.11$ & 0.566 \\
\hline $19-21^{a}$ & 0.85 & $0.80-0.90$ & $<0.001$ & 0.86 & $0.81-0.92$ & $<0.001$ \\
\hline $22-24^{a}$ & 0.83 & $0.79-0.87$ & $<0.001$ & 0.84 & $0.80-0.88$ & $<0.001$ \\
\hline \multicolumn{7}{|c|}{ Age (in 5 groups) } \\
\hline $15-16$ & 1.24 & $0.79-1.96$ & 0.351 & 1.35 & $0.82-2.23$ & 0.234 \\
\hline $17-18$ & 0.91 & $0.79-1.06$ & 0.229 & 0.93 & $0.80-1.09$ & 0.382 \\
\hline $19-20^{a}$ & 0.82 & $0.76-0.89$ & $<0.001$ & 0.82 & $0.76-0.90$ & $<0.001$ \\
\hline $21-22^{a}$ & 0.84 & $0.79-0.89$ & $<0.001$ & 0.85 & $0.80-0.91$ & $<0.001$ \\
\hline $23-24^{a}$ & 0.84 & $0.80-0.89$ & $<0.001$ & 0.85 & $0.80-0.90$ & $<0.001$ \\
\hline \multicolumn{7}{|l|}{ Repeated birth } \\
\hline \multicolumn{7}{|c|}{ Age (in 3 groups) } \\
\hline $15-18$ & 0.87 & $0.72-1.06$ & 0.181 & 0.90 & $0.73-1.10$ & 0.311 \\
\hline $19-21^{a}$ & 0.87 & $0.81-0.93$ & $<0.001$ & 0.88 & $0.83-0.95$ & $<0.001$ \\
\hline $22-24^{a}$ & 0.84 & $0.80-0.88$ & $<0.001$ & 0.85 & $0.82-0.89$ & $<0.001$ \\
\hline \multicolumn{7}{|c|}{ Age (in 5 groups) } \\
\hline $15-16$ & 2.15 & $0.54-8.57$ & 0.275 & 2.47 & $0.54-11.46$ & 0.245 \\
\hline $17-18$ & 0.87 & $0.72-1.07$ & 0.186 & 0.90 & $0.73-1.11$ & 0.316 \\
\hline $19-20^{\mathrm{a}}$ & 0.83 & 0.76-0.89 & $<0.001$ & 0.85 & $0.77-0.93$ & 0.001 \\
\hline $21-22^{a}$ & 0.86 & $0.80-0.92$ & $<0.001$ & 0.87 & $0.82-0.94$ & $<0.001$ \\
\hline $23-24^{a}$ & 0.85 & $0.80-0.90$ & $<0.001$ & 0.86 & $0.81-0.91$ & $<0.001$ \\
\hline
\end{tabular}

Abbreviations: OR-Odds ratio; $\mathrm{Cl}-95 \%$ Confidence Interval

${ }^{\mathrm{a}}$ Significant during Cochran test at 0.001 level; ${ }^{\mathrm{b}}$ Adjusted for region, type of residence and wealth quintile

and/or use modern family planning methods. Given the high rate of unmet need for modern contraception among married adolescents [21], policy initiatives/reforms such as providing exemption on contraception to adolescent mothers may be needed to achieve a reduction in the trend seen in this paper.

Our findings also suggest that prevention programs aimed at those from the poorest quintile may be warranted due to the high $\mathrm{RP} / \mathrm{RB}$ prevalence among this group. In the Philippines and other low- and middle-income countries (LMICs), attempts to reach out to households from the poorest sector have been undertaken through the Conditional Cash Transfer (CCT) Program [30, 31]. For example, the CCT program in Mexico has been found to indirectly reduce adolescent pregnancy and increase contraceptive use among adolescents and young adults [31]. The potential of cash incentive schemes can also be used as an opportunity to monitor and provide prevention programs to adolescent mothers, particularly within 24 months after their first pregnancy [10].
Our study uniquely explores the status of repeated pregnancy and birth in LMICs in the Asia-pacific Region. Most published reports on this topic are primarily from the USA, Europe, and Australia [32]. Of the few reports identified from LMICs, many used birth order (i.e. 2nd order or higher) and a different denominator (i.e. total number of adolescents) in the computation of prevalence. Despite the availability of possible data sources among LMICs [33], few studies have attempted to look specifically at the distribution of adolescents and young adults with RP/RB. Most of the reports available may include vital statistics which is limited to those only with livebirths and does not necessarily account for previous unsuccessful pregnancies.

By placing RP as an issue of crucial importance to the public health especially of LMICs, our paper makes a significant contribution to the literature calling for improvement of sexual and reproductive health of adolescents. The Global Strategy for Adolescent Health for 2030 recognized childbirth and pregnancy complications as one of the two leading causes of death among 1519 year old girls [34] —addressing RP would help to reduce this. The absence of a reduction in RP trend over 20 years that we identified, signals the need for secondary prevention programs in line with WHO recommendations [35].

This study finds strength in our use of nationally-representative individual datasets instead of aggregate estimates. This prevents the risk of producing results affected by the ecological fallacy, particularly in the analysis of year-age interaction. Furthermore, we were able to perform more thorough analyses such as the adjustment of trend estimates for confounders (i.e. wealth quintile, region, and type of residence).

\section{Limitations}

Our study also has limitations. Recall bias and under-reporting are likely to produce bias in any surveys covering information of a sensitive nature. Insufficient record validation is common across the DHS surveys from all countries. However, the DHS' survey procedure enables cross-checking through repeated questions during the interview to reduce the effect of this validation issue. Additionally, our findings may not be comparable to longitudinal studies from developed countries that defined RP as an adolescent who became pregnant within 12-24 months of her first pregnancy/ delivery.

\section{Future research}

In addition to cross-sectional analyses that measure RP prevalence, epidemiological investigations are needed to explore the causes and outcomes of RP. Studies conducted in LMICs may identify different associations and dynamics due to the psychosocial and cultural 
Table 3 Trend analysis of repeated pregnancy and birth among adolescents per socio-geographic variable in each age group

\begin{tabular}{|c|c|c|c|c|c|c|c|c|c|c|c|c|c|c|c|c|c|c|}
\hline \multirow{3}{*}{$\begin{array}{l}\text { Year } x \\
\text { Characteristics } \\
\text { Contrasts) }\end{array}$} & \multicolumn{9}{|c|}{ Repeated pregnancy } & \multicolumn{9}{|c|}{ Repeated birth } \\
\hline & \multicolumn{3}{|c|}{$15-18$ years old } & \multicolumn{3}{|c|}{ 19-21 years old } & \multicolumn{3}{|c|}{ 22-24 years old } & \multicolumn{3}{|c|}{$15-18$ years old } & \multicolumn{3}{|c|}{ 19-21 years old } & \multicolumn{3}{|c|}{ 22-24 years old } \\
\hline & $\mathrm{OR}$ & $\mathrm{Cl}$ & $p$ & $\mathrm{OR}$ & $\mathrm{Cl}$ & $p$ & $\mathrm{OR}$ & $\mathrm{Cl}$ & $p$ & $\overline{O R}$ & $\mathrm{Cl}$ & $p$ & $\overline{\mathrm{OR}}$ & $\mathrm{Cl}$ & $\mathrm{p}$ & OR & $\mathrm{Cl}$ & $p$ \\
\hline \multicolumn{19}{|l|}{ Region } \\
\hline Luzon & 0.82 & $\begin{array}{l}0.66- \\
1.02\end{array}$ & 0.08 & 0.88 & $\begin{array}{l}0.81- \\
0.96\end{array}$ & 0.004 & 0.80 & $\begin{array}{l}0.75- \\
0.86\end{array}$ & $<0.001$ & 0.86 & $\begin{array}{l}0.65- \\
1.14\end{array}$ & 0.291 & 0.92 & $\begin{array}{l}0.84- \\
1.02\end{array}$ & 0.118 & 0.84 & $\begin{array}{l}0.79- \\
0.90\end{array}$ & $<0.001$ \\
\hline Visayas & 1.09 & $\begin{array}{l}0.74- \\
1.61\end{array}$ & 0.65 & 0.74 & $\begin{array}{l}0.64- \\
0.86\end{array}$ & $<0.001$ & 0.84 & $\begin{array}{l}0.73- \\
0.93\end{array}$ & 0.001 & 0.94 & $\begin{array}{l}0.57- \\
1.55\end{array}$ & 0.801 & 0.77 & $\begin{array}{l}0.65- \\
0.91\end{array}$ & 0.002 & 0.81 & $\begin{array}{l}0.72- \\
0.91\end{array}$ & $<0.001$ \\
\hline Mindanao & 1.04 & $\begin{array}{l}0.82- \\
1.30\end{array}$ & 0.763 & 0.85 & $\begin{array}{l}0.77- \\
0.94\end{array}$ & 0.001 & 0.91 & $\begin{array}{l}0.84- \\
0.93\end{array}$ & 0.017 & 0.86 & $\begin{array}{l}0.63- \\
1.18\end{array}$ & 0.358 & 0.82 & $\begin{array}{l}0.74- \\
0.91\end{array}$ & $<0.001$ & 0.87 & $\begin{array}{l}0.80- \\
0.94\end{array}$ & 0.001 \\
\hline
\end{tabular}

Type of residence

\begin{tabular}{|c|c|c|c|c|c|}
\hline Urban & 0.88 & $\begin{array}{l}0.69- \\
1.11\end{array}$ & 0.282 & 0.88 & $\begin{array}{l}0.80- \\
0.96\end{array}$ \\
\hline Rural & 0.98 & $\begin{array}{l}0.82- \\
1.18\end{array}$ & 0.85 & 0.83 & $\begin{array}{l}0.76- \\
0.90\end{array}$ \\
\hline \multicolumn{6}{|c|}{ Nealth quintile } \\
\hline Poorest & 0.95 & $\begin{array}{l}0.75- \\
1.20\end{array}$ & 0.677 & 0.9 & $\begin{array}{l}0.81- \\
1.00\end{array}$ \\
\hline Poorer & 0.90 & $\begin{array}{l}0.69- \\
1.19\end{array}$ & 0.463 & 0.77 & $\begin{array}{l}0.69- \\
0.86\end{array}$ \\
\hline Middle & 0.98 & $\begin{array}{l}0.71- \\
1.36\end{array}$ & 0.905 & 0.92 & $\begin{array}{l}0.80- \\
1.05\end{array}$ \\
\hline Richer & 1.01 & $\begin{array}{l}0.66- \\
1.53\end{array}$ & 0.97 & 0.89 & $\begin{array}{l}0.75- \\
1.05\end{array}$ \\
\hline Richest & 0.69 & $\begin{array}{l}0.27- \\
1.80\end{array}$ & 0.45 & 0.89 & $\begin{array}{l}0.70- \\
1.11\end{array}$ \\
\hline
\end{tabular}

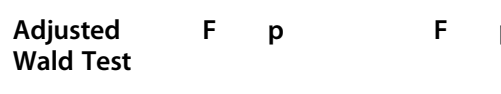

Region

$\begin{array}{llllll}\text { Luzon vs. } & 1.57 & 0.211 & & 3.69 & 0.054 \\ \text { Visayas } & & & & & \\ \text { Luzon vs. } & 2.04 & 0.154 & 0.30 & 0.5 \\ \text { Mindanao } & & & & & \\ \text { Visayas vs. } & 0.06 & 0.812 & 2.07 & 0.1 \\ \text { Mindanao } & & & & \end{array}$

Type of residence

\begin{tabular}{|c|c|c|c|c|c|c|c|c|c|c|c|c|}
\hline $\begin{array}{l}\text { Urban vs. } \\
\text { Rural }\end{array}$ & 0.54 & 0.462 & 0.94 & 0.33 & 2.62 & 0.106 & 0.00 & 0.951 & 5.21 & 0.023 & 2.34 & 0.127 \\
\hline \multicolumn{13}{|l|}{ Vealth quintile } \\
\hline $\begin{array}{l}\text { Poorest vs. } \\
\text { Poorer }\end{array}$ & 0.07 & 0.787 & 4.29 & 0.039 & 0.13 & 0.718 & 0.49 & 0.485 & 1.22 & 0.289 & 0.04 & 0.844 \\
\hline $\begin{array}{l}\text { Poorest vs. } \\
\text { Middle }\end{array}$ & 0.02 & 0.876 & 0.03 & 0.87 & 0.20 & 0.656 & 0.01 & 0.907 & 0.31 & 0.58 & 0.35 & 0.55 \\
\hline $\begin{array}{l}\text { Poorest vs. } \\
\text { Richer }\end{array}$ & 0.07 & 0.797 & 0.03 & 0.853 & 1.43 & 0.232 & 0.28 & 0.595 & 0.60 & 0.44 & 2.74 & 0.098 \\
\hline $\begin{array}{l}\text { Poorest vs. } \\
\text { Richest }\end{array}$ & 0.40 & 0.528 & 0.02 & 0.883 & 9.18 & 0.003 & NA & & 0.65 & 0.419 & 5.00 & 0.023 \\
\hline $\begin{array}{l}\text { Poorer vs. } \\
\text { Middle }\end{array}$ & 0.15 & 0.70 & 3.64 & 0.057 & 0.01 & 0.933 & 0.16 & 0.689 & 1.90 & 0.169 & 0.14 & 0.705 \\
\hline $\begin{array}{l}\text { Poorer vs. } \\
\text { Richer }\end{array}$ & 0.18 & 0.668 & 1.87 & 0.172 & 0.83 & 0.363 & 0.01 & 0.93 & 2.27 & 0.133 & 2.37 & 0.124 \\
\hline $\begin{array}{l}\text { Poorer vs. } \\
\text { Richest }\end{array}$ & 0.28 & 0.599 & 1.14 & 0.285 & 7.86 & 0.005 & NA & & 1.96 & 0.162 & 4.39 & 0.036 \\
\hline
\end{tabular}

$\begin{array}{llllllllllllll}\mathbf{0 . 0 0 6} & 0.80 & 0.74- & <\mathbf{0 . 0 0 1} & 0.89 & 0.62- & 0.528 & 0.95 & 0.85- & 0.288 & 0.81 & 0.75- & <\mathbf{0 . 0 0 1} \\ & & 0.86 & & & & 1.27 & & & 1.05 & & & 0.87 & \\ & \mathbf{0 . 0 0 1} & 0.86 & 0.81- & <\mathbf{0 . 0 0 1} & 0.88 & 0.69- & 0.307 & 0.81 & 0.74- & <\mathbf{0 . 0 0 1} & 0.87 & 0.82- & <\mathbf{0 . 0 1 1}\end{array}$

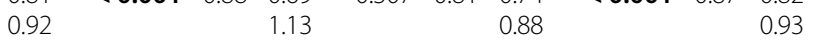
$\begin{array}{lllllllll}0.056 & 0.90 & 0.81- & \mathbf{0 . 0 3} & 0.82 & 0.59- & 0.239 & 0.88 & 0.79-\end{array}$ 0.99 $<0.001 \quad 0.87 \quad 0.79-$ $0.202 \quad 0.87 \quad 0.79$ 0.95 $\mathbf{0 . 0 0 5} \quad 0.97 \quad 0.70-\quad 0.833 \quad 0.80 \quad 0.70-$ $\begin{array}{llllll}0.003 & 0.85 & 0.51- & 0.551 & 0.93 & 0.79\end{array}$ $\begin{array}{llll}0.51- & 0.551 & 0.93 & 0.79- \\ 1.44 & & & 1.10\end{array}$

$\mathbf{0 . 0 1 8} 0.90 \quad 0.82-$ 1.00

$\mathbf{0 . 0 0 1} \quad 0.89 \quad 0.81-$ 0.98

$0.379 \quad 0.87 \quad 0.79$ 0.96

$\begin{array}{lllllllll}0.16 & 0.82 & 0.72- & <0.001 & 1.00 & 0.53- & 0.993 & 0.96 & 0.79-\end{array}$ 0.91 1.88 1.17

$0.298 \quad 0.68 \quad 0.59-\quad<0.001 \quad N C$ 0.79

$0.99 \quad 0.76-$ 1.29

$0.685 \quad 0.79 \quad 0.70-$ 0.89

$0.927 \quad 0.73 \quad 0.62-\quad<0.001$

\section{F p}

\section{F p}

F p

F $\quad$ p

$0.30 \quad 0.585$

$0.47 \quad 0.493$

$6.01 \quad 0.014$

$0.00 \quad 0.967$

$2.56 \quad 0.110$

$1.06 \quad 0.302$

$1.86 \quad 0.173$

$0.08 \quad 0.782$

$0.47 \quad 0.491$

0.041

0.018

0.004

$<0.001$

.86 
Table 3 Trend analysis of repeated pregnancy and birth among adolescents per socio-geographic variable in each age group (Continued)

\begin{tabular}{|c|c|c|c|c|c|c|c|c|c|c|c|c|c|c|c|c|c|c|}
\hline \multirow{3}{*}{$\begin{array}{l}\text { (Year } \mathrm{x} \\
\text { Characteristics } \\
\text { Contrasts) }\end{array}$} & \multicolumn{9}{|c|}{ Repeated pregnancy } & \multicolumn{9}{|c|}{ Repeated birth } \\
\hline & \multicolumn{3}{|c|}{$15-18$ years old } & \multicolumn{3}{|c|}{ 19-21 years old } & \multicolumn{3}{|c|}{$22-24$ years old } & \multicolumn{3}{|c|}{$15-18$ years old } & \multicolumn{3}{|c|}{ 19-21 years old } & \multicolumn{3}{|c|}{$22-24$ years olc } \\
\hline & $\mathrm{OR}$ & $\mathrm{Cl}$ & $p$ & $\mathrm{OR}$ & $\mathrm{Cl}$ & $\mathrm{p}$ & $\mathrm{OR}$ & $\mathrm{Cl}$ & $p$ & $\mathrm{OR}$ & $\mathrm{Cl}$ & $p$ & $\mathrm{OR}$ & $\mathrm{Cl}$ & $p$ & $\mathrm{OR}$ & $\mathrm{Cl}$ & $p$ \\
\hline $\begin{array}{l}\text { Middle vs. } \\
\text { Richer }\end{array}$ & 0.01 & 0.915 & & 0.09 & 0.763 & & 0.75 & 0.387 & & 0.14 & 0.709 & & 0.06 & 0.801 & & 1.47 & 0.226 & \\
\hline $\begin{array}{l}\text { Middle vs. } \\
\text { Richest }\end{array}$ & 0.45 & 0.504 & & 0.06 & 0.807 & & 7.63 & 0.006 & & NA & & & 0.15 & 0.70 & & 3.25 & 0.072 & \\
\hline $\begin{array}{l}\text { Richer vs. } \\
\text { Richest }\end{array}$ & 0.51 & 0.475 & & 0.00 & 0.999 & & 3.78 & 0.052 & & NA & & & 0.03 & 0.866 & & 0.65 & 0.42 & \\
\hline
\end{tabular}

Abbreviations: OR-Odds ratio; Cl-95\% Confidence Interval; $\mathrm{p}-\mathrm{p}$ value; F-F statistic; NC-No cases; NA-Not applicable; OR-Odds ratio

Data captured in bold are highly significant

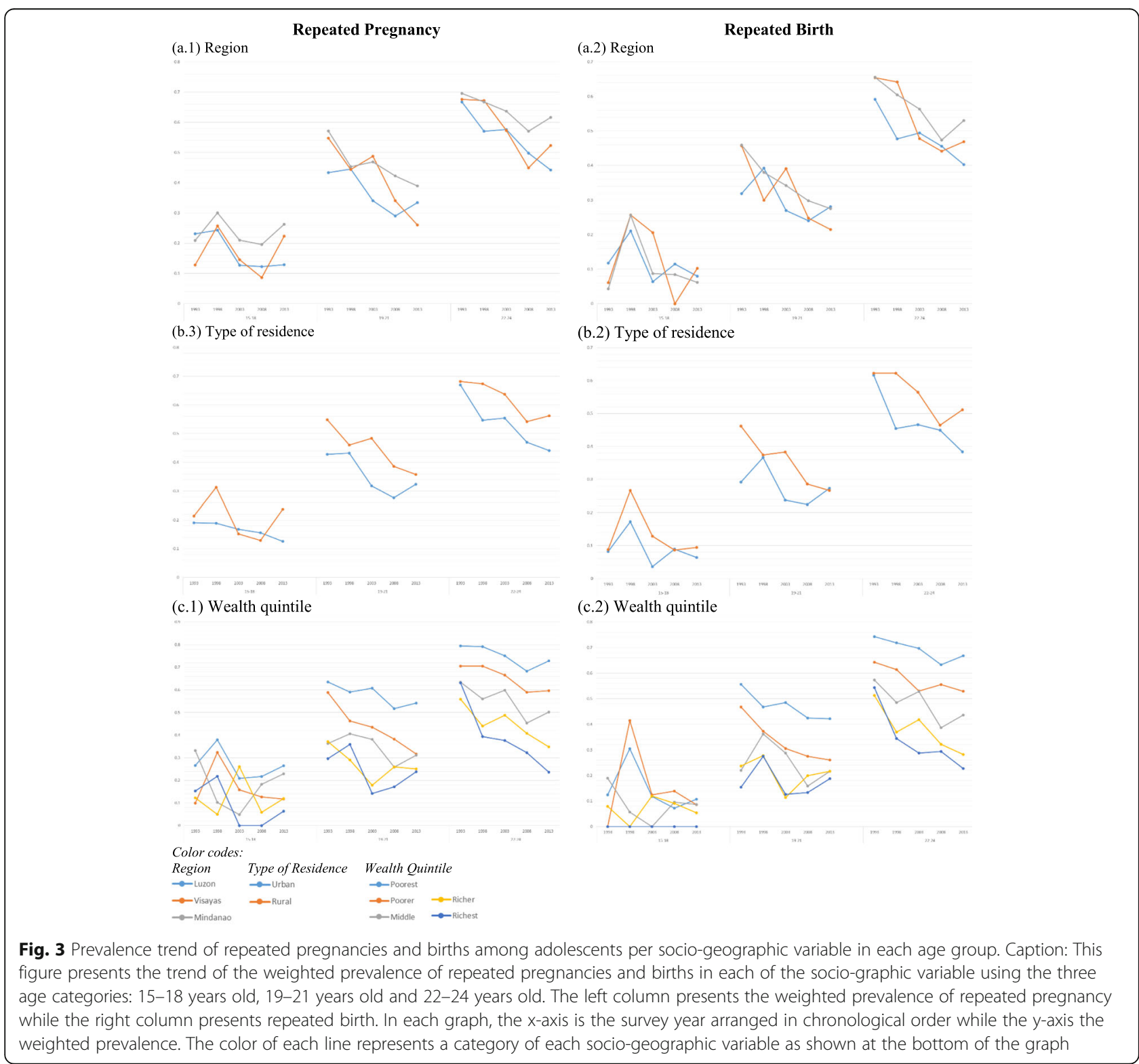




\section{Appendix}

Table 4 Characteristics of National Demographic and Health Survey (NDHS) Philippines from 1993 to 2013

\begin{tabular}{|c|c|c|c|c|c|}
\hline \multirow[t]{2}{*}{ Characteristics } & \multicolumn{5}{|l|}{ Year } \\
\hline & 2013 & 2008 & 2003 & 1998 & 1993 \\
\hline \multicolumn{6}{|l|}{ Sampling } \\
\hline Frame & 2010 Census & 2000 Census & 2000 Census & 1995 Census & 1990 Census \\
\hline Design & $\begin{array}{l}\text { Stratified Two-stage } \\
\text { First stage: Systematic } \\
\text { selection of } 800 \text { Enumeration } \\
\text { Areas (EAs) distributed by } \\
\text { region (17) and type of } \\
\text { residence (rural, urban) } \\
\text { Second stage: Systematic } \\
\text { selection of } 20 \text { housing } \\
\text { units per EA (maximum } \\
\text { of } 3 \text { households per unit) }\end{array}$ & $\begin{array}{l}\text { Stratified Three-stage } \\
\text { First stage: Selection } \\
\text { of PSUs } \\
\text { Second stage: } \\
\text { Selection of } 794 \text { EAs } \\
\text { Third stage: Selection } \\
\text { of } 17 \text { housing units } \\
\text { per EA through } \\
\text { systematic random } \\
\text { sampling (maximum of } \\
3 \text { households per unit) }\end{array}$ & $\begin{array}{l}\text { Stratified Three-stage } \\
\text { Cluster } \\
\text { First stage: } \\
\text { Selection of } 819 \text { PSUs } \\
\text { Second Stage: Selection } \\
\text { of EAs per PSU } \\
\text { Third stage: Systematic } \\
\text { selection of } 17 \\
\text { households per EA }\end{array}$ & $\begin{array}{l}\text { Stratified Two-stage } \\
\text { First stage: Selection } \\
\text { of } 752 \text { EAs on } 16 \text { regions } \\
\text { Second Stage: Systematic } \\
\text { selection of households } \\
\text { in urban while cluster } \\
\text { sampling among rural areas }\end{array}$ & $\begin{array}{l}\text { Stratified Two-stage } \\
\text { First stage: Selection } \\
\text { of } 750 \text { PSUs distributed } \\
\text { among } 14 \text { regions } \\
\text { Second stage: Selection } \\
\text { of } 20 \text { households per PSU }\end{array}$ \\
\hline \multicolumn{6}{|l|}{ Response Rates } \\
\hline Households & 99.2 & 99.3 & 99.1 & 98.7 & 99.2 \\
\hline Women (15-49 years old) & 98.3 & 98.3 & 97.8 & 97.2 & 98 \\
\hline \multicolumn{6}{|l|}{ Sample Size } \\
\hline Households & 14,804 & 12,469 & 12,586 & 12,407 & 12,995 \\
\hline $\begin{array}{l}\mathrm{n} \text { of Women (15-19 years } \\
\text { old) } \\
\text { Weighted \% distribution }\end{array}$ & $\begin{array}{l}3261 \\
20 \%\end{array}$ & $\begin{array}{l}2766 \\
20.2 \%\end{array}$ & $\begin{array}{l}2646 \\
19.4 \%\end{array}$ & $\begin{array}{l}2949 \\
20.9 \%\end{array}$ & $\begin{array}{l}3139 \\
21 \%\end{array}$ \\
\hline $\begin{array}{l}\mathrm{n} \text { of Women (15-24 years } \\
\text { old) }\end{array}$ & $\begin{array}{l}6070 \\
37.3 \%\end{array}$ & $\begin{array}{l}4909 \\
36 \%\end{array}$ & $\begin{array}{l}4860 \\
35.6 \%\end{array}$ & $\begin{array}{l}5190 \\
37.3 \%\end{array}$ & $\begin{array}{l}5741 \\
38.6 \%\end{array}$ \\
\hline
\end{tabular}

characteristics of and attitudes towards adolescent mothers in these countries. This type of study not only directs the development of specialized perinatal care, and psychosocial and welfare support but also places priority on those adolescents with RP.

A multi-country analysis would also be beneficial in obtaining a broader RP status especially in countries with similar characteristics. This would help international organizations to implement immediate action for RP in a global approach and prioritize countries with a high RP burden. Additionally, projection of RP prevalence at least until 2030 using country-level determinants such as contraceptive prevalence, poverty, literacy, and maternal-child mortality rates, may facilitate target setting for this potential adolescent reproductive health indicator.

\section{Conclusion}

There is a constant trend of one in every five adolescent mothers in the Philippines experiencing repeated pregnancy from 1993 to 2013 (across all regions, type of residence, and socio-economic status). These findings indicate the need for secondary prevention programs, particularly among the poorest households. Epidemiological investigations are also necessary to explore the causes and impacts of repeated pregnancy on maternal, child, and neonatal health in the Philippines and other low- and middle-income countries.

\section{Abbreviations}

CCT: Conditional Cash Transfer; Cl: 95\% Confidence Interval; DHS: Demographic and Health Survey; FP: Family planning; LMICs: Low- and middle-income countries; OR: Odds ratio; RB: Repeated birth; RP: Repeated Pregnancy; WHO: World Health Organization; WtPrevRB: Weighted RB prevalence; WtPrevRP: Weighted RP prevalence

\section{Acknowledgements}

We also acknowledge the Demographic and Health Surveys Program for allowing us to access the all Philippine DHS datasets. This study was presented at the 15th World Congress on Public Health, Australia, April 3-7, 2017.

Funding

This study was supported by the University of Queensland International Scholarship.

\section{Availability of data and materials}

The datasets analyzed during the current study are not publicly available but can be requested from the DHS Program data managers.

\section{Authors' contributions}

JM conceptualized the study design, prepared the datasets, conducted the analysis, and drafted and revised the manuscript. KB conceptualized the study design, conducted the analysis, and revised the manuscript. RA conceptualized the study design, supervised the data analysis, and revised the manuscript. All authors approved the final manuscript as submitted and agreed to be accountable for all aspects of the work.

\section{Ethics approval and consent to participate}

This study underwent an expedited review and was approved by the University of Queensland - School of Public Health Ethics Committee on April 112016.

Consent for publication Not applicable. 


\section{Competing interests}

The authors declare that they have no competing interests. The authors have no financial relationships relevant to this article to disclose.

\section{Publisher's Note}

Springer Nature remains neutral with regard to jurisdictional claims in published maps and institutional affiliations.

\section{Author details}

${ }^{1}$ School of Public Health, The University of Queensland, Herston, QLD, Australia. ${ }^{2}$ Institute for Social Science Research, The University of Queensland, Indooroopilly, QLD, Australia. ${ }^{3}$ Centre for Youth Substance Abuse Research, The University of Queensland, Herston, QLD, Australia.

\section{Received: 25 September 2017 Accepted: 21 October 2018}

Published online: 06 November 2018

\section{References}

1. World Health Organization-Western Pacific Region. Fact Sheet on Adolescent Health. 2015; http://www.wpro.who.int/mediacentre/factsheets/ docs/fs_201202_adolescent_health/en/. Accessed June 30, 2015, 2015.

2. UNFPA, UNESCO and WHO. Sexual and Reproductive Health of young people in Asia and the Pacific: A review of issues, policies and programmes. Bangkok: UNFPA; 2015

3. Philippine Statistics Authority, and ICF International. Philippines National Demographic and Health Survey 2013. Manila, Philippines, and Rockville, Maryland, USA: Philippine Statistics Authority, and ICF International; 2014

4. Department of Health-Philippines. In: Health Do, editor. National policy and strategic framework on adolescent health and Development. Philippines: Department of Health; 2013.

5. Department of Health-Philippines. Behavior change communication strategies for preventing preventing adolescent pregnancy. Philippines: Department of Health; 2012. https://www.doh.gov.ph/sites/default/files/ publications/SourcebookBCCStrategiesPreventingAdolescentPregnancy.pdf Accessed 19 Feb 2016

6. Natividad J. Teenage pregnancy in the Philippines: trends, correlates and data sources. J ASEAN Fed Endocr Soc. 2013;28(1):30-7.

7. Gavin L, Warner L, O'Neil ME, et al. Vital signs: repeat births among teens United States, 2007-2010. Mmwr-Morbid Mortal W. 2013;62(13):249-55.

8. Rowlands S. Social predictors of repeat adolescent pregnancy and focussed strategies. Best Pract Res Clin Obstet Gynaecol. 2010;24(5): 605-16.

9. Lewis LN, Doherty DA, Hickey M, Skinner SR. Predictors of sexual intercourse and rapid-repeat pregnancy among teenage mothers: an Australian prospective longitudinal study. Med J Aust. 2010;193(6):338-42.

10. Stevens-Simon C, Kelly L, Singer D, Nelligan D. Reasons for first teen pregnancies predict the rate of subsequent teen conceptions. Pediatrics. 1998;101(1):E8.

11. Capanzana MV, Aguila DV, Javier CA, Mendoza TS, Santos-Abalos VM. Adolescent pregnancy and the first 1000 days (the Philippine situation). Asia Pac J Clin Nutr. 2015;24(4):759-66.

12. Hussain R, Finer L. Unintended pregnancy and unsafe abortion in the Philippines: context and consequences. In Brief. 2013;3 https://www. guttmacher.org/sites/default/files/report_pdf/ib-unintended-pregnancyphilippines.pdf. Accessed 15 June 2018.

13. Salvador JT, Sauce BRJ, Alvarez MOC, Rosario AB. The phenomenon of teenage pregnancy in the Philippines. Eur Scientific J. 2016;12(32).

14. Ganchimeg T, Ota E, Morisaki N, et al. Pregnancy and childbirth outcomes among adolescent mothers: a World Health Organization multicountry study. BJOG Int J Obstet Gynaecol. 2014;121:40-8.

15. Association of Maternal \& Child Health Programs. Life course indicator: Repeat teen Birth Life course indicator online tool 2014; http://www.amchp. org/programsandtopics/data-assessment/LifeCourselndicatorDocuments/LC54\%20Teen\%20Births_Final-9-10-2014.pdf. Accessed February 12, 2016

16. Penman-Aguilar A, Carter, M., Snead, M. C., Kourtis, A. P. Socioeconomic disadvantage as a social determinant of teen childbearing in the U.S. Vol 1282013

17. National Campaign to Prevent Teen and Unplanned Pregnancy. Counting it up: The public costs of teen childbearing. 2014; https:// thenationalcampaign.org/resource/public-costs-teen-childbearing-unitedstates. Accessed August 22, 2014.
18. Guttmacher Institute. Sexual and reproductive health of young women in the Philippines: 2013 data Update 2015.

19. Knoll LJ, Magis-Weinberg L, Speekenbrink M, Blakemore S-J. Social influence on risk perception during adolescence. Psychol Sci. 2015;26(5):583-92.

20. Melgar JD, Melgar AR, Cabigon JV. Family Planning in the Philippines. In: Zaman W, Masnin H, Loftus J, editors. Family Planning in Asia \& the Pacific: Addressing the Challenges. Malaysia: International Council on Management of Population Programmes; 2012. http://icomp.org.my/ FP\%20in\%20Asia\%20and\%20the\%20Pacific\%20Jan\%202012.pdf.

21. Demographic Research and Development Foundation, and University of the Philippines Population Institute. 2013 YAFS4 Key Findings. Quezon City, Philippines: Demographic Research and Development Foundation, and University of the Philippines Population Institute; 2014

22. Ogena NA. Development concept of adolescence: the case of adolescents in the Philippines. Philipp Popul Rev. 2014;3(1).

23. Varga CA, Zosa-Feranil I. Adolescent reproductive health in the Philippines: status, policies, programs, and issues. Washington, DC: The Futures Group International, POLICY Project; 2003

24. Department of Health-Philippines. Adolescent \& Youth Health (AYH) policy. Manila: Department of Health; 2000

25. Sedgh G, Finer LB, Bankole A, Eilers MA, Singh S. Adolescent pregnancy, birth, and abortion rates across countries: levels and recent trends. J Adolesc Health. 2015;56(2):223-30.

26. Corcoran J, Pillai VK. Effectiveness of secondary pregnancy prevention programs: a meta-analysis. Res Soc Work Pract. 2007;17(1):5-18.

27. Pogoy AM, Verzosa R. Coming NS, Agustino RG. Lived experiences of early pregnancy among teenagers: a phenomenological study. Eur Scientific J. 2014;10(2).

28. Government of the Philippines. Republic act no. 10354: An act providing for a national policy on responsible parenthood and reproductive healthy on responsible parenthood and reproductive health. In: Gazette-Philippines. 2012; Document number:10534. http://www.gov.ph/2012/12/21/republic-act-no10354/.

29. Chandra-Mouli V, McCarraher DR, Phillips SJ, Williamson NE, Hainsworth G. Contraception for adolescents in low and middle income countries: needs, barriers, and access. Reprod Health 2014;11(1):1.

30. World Bank. Philippines conditional cash transfer program : impact evaluation 2012. Washington, DC: World Bank; 2013.

31. Darney BG, Weaver MR, Sosa-Rubi SG, et al. The Oportunidades conditional cash transfer program: effects on pregnancy and contraceptive use among young rural women in Mexico. Int Perspect Sex Reprod Health. 2013;39(4): 205-14.

32. Maravilla, JC, Betts, KS, Couto e Cruz, C, and Alati, R. Factors influencing repeated teenage pregnancy: a review and meta-analysis. Am J Obstet Gynecol. 2017; 217(5). https://doi.org/10.1016/j.ajog.2017.04.02.

33. Gray N, Azzopardi P, Kennedy E, Willersdorf E, Creati M. Improving adolescent reproductive health in Asia and the Pacific. Asia Pac J Public Health. 2013;25(2):134-44.

34. Every Woman Every Child Strategy and Coordination Group. Global Strategy for Women's, Children's and Adolescent's Health 2016-2030. Italy: United Nations; 2015

35. Chandra-Mouli V, Camacho AV, Michaud P-A. WHO guidelines on preventing early pregnancy and poor reproductive outcomes among adolescents in developing countries. J Adolesc Health. 2013;52(5):517.

Ready to submit your research? Choose BMC and benefit from:

- fast, convenient online submission

- thorough peer review by experienced researchers in your field

- rapid publication on acceptance

- support for research data, including large and complex data types

- gold Open Access which fosters wider collaboration and increased citations

- maximum visibility for your research: over $100 \mathrm{M}$ website views per year

At BMC, research is always in progress.

Learn more biomedcentral.com/submission 